OPEN ACCESS

Edited by:

Marco Solmi,

University of Padua, Italy

Reviewed by:

Kenji Hashimoto,

Chiba University, Japan

Qian Ren,

Hebei Medical University, China

${ }^{*}$ Correspondence:

Ulderico Freo

ulderico.freo@unipd.it

Specialty section:

This article was submitted to

Perception Science,

a section of the journal

Frontiers in Neuroscience

Received: 17 July 2020

Accepted: 04 March 2021

Published: 11 May 2021

Citation:

Freo U, Brugnatelli V, Turco $F$ and

Zanette G (2021) Analgesic

and Antidepressant Effects of the

Clinical Glutamate Modulators

Acetyl-L-Carnitine and Ketamine.

Front. Neurosci. 15:584649.

doi: 10.3389/fnins.2021.584649

\section{Analgesic and Antidepressant Effects of the Clinical Glutamate Modulators Acetyl-L-Carnitine and Ketamine}

\author{
Ulderico Freo $^{1 *}$, Viola Brugnatelli2, Fabio Turco ${ }^{3}$ and Gastone Zanette ${ }^{2}$ \\ ${ }^{1}$ Section of Anesthesiology and Intensive Care, Department of Medicine-DIMED, University of Padua, Padua, Italy, ${ }^{2}$ Section \\ of Dentistry, Department of Neurosciences-DNS, University of Padua, Padua, Italy, ${ }^{3}$ Molecular Biology and Biochemistry \\ Laboratory, Department of Neurogastroenterology, University of Naples Federico II, Naples, Italy
}

Pain and depression are leading causes of disability and of profound social and economic burden. Their impact is aggravated by their chronicity and comorbidity and the insufficient efficacy of current treatments. Morphological and functional metabolism studies link chronic pain and depressive disorders to dysfunctional neuroplastic changes in fronto-limbic brain regions that control emotional responses to painful injuries and stressful events. Glutamate modulators are emerging new therapies targeting dysfunctional brain areas implicated in the generation and maintenance of chronic pain and depression. Here, we report the effects of two clinically approved glutamate modulators: acetyl-L-carnitine (ALCAR) and S,R( \pm )ketamine (KET). ALCAR is a natural neurotrophic compound currently marketed for the treatment of neuropathies. KET is the prototypical non-competitive antagonist at $\mathrm{N}$-methyl-D-aspartate glutamate receptors and a clinically approved anesthetic. Although they differ in pharmacological profiles, ALCAR and KET both modulate aminergic and glutamatergic neurotransmissions and pain and mood. We assessed in rats the effects of ALCAR and KET on cerebral metabolic rates for glucose ( $\mathrm{rCMRglc}$ ) and assessed clinically the effects of ALCAR in chronic pain and of KET in post-operative pain. ALCAR and KET increased rCMRglc at similar degrees in prefrontal, somatosensory, and cingulate cortices, and KET increased rCMRglc at a different, much larger, degree in limbic and dopaminergic areas. While rCMRglc increases in prefrontal cortical areas have been associated with analgesic and antidepressant effects of ALCAR and KET, the marked metabolic increases KET induces in limbic and dopaminergic areas have been related to its psychotomimetic and abuse properties. In patients with chronic neuropathic pain, ALCAR (1,000 mg/day) yielded to a fast ( 2 weeks) improvement of mood and then of pain and quality of life. In day-surgery patients, KET improved dischargeability and satisfaction. In obese patients undergoing bariatric surgery, a single, low dose of KET $(0.5 \mathrm{mg} / \mathrm{kg})$ at induction of anesthesia determined a very fast (hours) amelioration of post-operative depression and pain and an opioid-sparing effect. These findings indicate that ALCAR and KET, two non-selective glutamate modulators, still offer viable therapeutic options in comorbid pain and depression.

Keywords: acetyl-L-carnitine, ketamine, regional cerebral metabolic rates for glucose, pain, depression 


\section{INTRODUCTION}

Chronic pain and depression are leading causes of disability that are frequently encountered comorbidly in a variety of clinical conditions, sharing genetic and psychological risk factors, a relapsing-chronic course, and neurobiological features (Bair et al., 2003; Meyer et al., 2007; Kroenke et al., 2011; Global Burden of Disease Study 2013 Collaborators, 2015; D'Amato et al., 2016; Freo et al., 2019a,b). In the chronic pain patient, the presence of a major depression is associated with reduced function, poorer outcome, and expanded health-care costs; in the depressed patient, pain is a frequent presenting symptom and a predictor of treatment response (Bair et al., 2003; Meyer et al., 2007; Kroenke et al., 2011; D’Amato et al., 2016).

Because of global aging, the prevalence of pain, depression, and comorbid pain and depression is expected to increase (Molton and Terrill, 2014; Chui et al., 2015). As currently available therapies do not work for many patients, new pharmacological approaches are deemed essential. Glutamate drugs are emerging treatments for pain and depression (Henter et al., 2017; Pereira and Goudet, 2019). Newly developed, receptor-selective glutamate compounds are often hampered by the uncertain toxicity and the tolerability profile; older, nonselective agents are available for different routes of administration [i.e., oral (PO), intramuscular (IM), and intravenous (IV)] and continue to be investigated actively (Henter et al., 2017; Pereira and Goudet, 2019).

We assessed the effects of two clinical glutamate modulators, acetyl-L-carnitine (ALCAR) and ketamine (KET), on regional glucose cerebral metabolism and on patients with comorbid pain and depression. This review summarizes our pre-clinical and clinical research on ALCAR and KET.

\section{PAIN AND DEPRESSION}

According to the International Association for the Study of Pain, pain can be roughly classified on the basis of mechanism as nociceptive, neuropathic, or nociplastic pain. Nociceptive pain reflects the normal functioning of the somatosensory systems responding in a stimulus-dependent manner to an actual or potential damage of non-neuronal tissue and is treated with conventional non-steroidal anti-inflammatory and/or opioid analgesics (Freynhagen et al., 2019). In contrast to nociceptive pain, neuropathic pain is induced by a lesion or disease of the somatosensory nervous system that generates and maintains spontaneous pain and positive and negative sensory disturbances, independently from stimuli (Freynhagen et al., 2019; Scholz et al., 2019). Neuropathic pain worsens cognitive and mood functions and quality of life and is treated with antiepileptic and/or antidepressant drugs targeting the abnormal somatosensory nervous systems (Nicholson and Verma, 2004; Fornasari, 2017). Recently, the International Association for the Study of Pain defined nociplastic pain as pain occurring from an altered nociception in spite of no evidence of any tissue damage (Freynhagen et al., 2019). Multiple pain mechanisms may be active at the same time in the single patient, making diagnosis and treatment more difficult (Freynhagen et al., 2019). Finally, pain is considered chronic if it lasts longer than the 3 months' healing time.

Neuropathic pain is often chronic, and neuropathic symptoms (i.e., "component") are frequently reported and aggravate painful, non-primary neurological conditions in spite of no demonstrable neuronal injury (Freo et al., 2019b, 2020; Freynhagen et al., 2019; Scholz et al., 2019). Because of the loss of protective features and the damage they cause, chronic and neuropathic pain are viewed as "disease states" (Costigan et al., 2009).

Although they often coexist and complicate each other's outcome, the exact relation between chronic pain and depression has yet to be elucidated (Bair et al., 2003; Sheng et al., 2017). Most studies report an increased sensitivity to experimental pain and, therefore, a decreased pain threshold in depressed compared to non-depressed subjects especially when emotional aspects of experimental pain are taken into account (Ushinsky et al., 2013); probably because of an altered sensation, unexplained pain is common in depression and is often the presenting and prevailing symptom (Bair et al., 2003). Stressful events may facilitate chronification of both pain and of negative/depressed mood; personal experiences such emotional strain, childhood traumatic experiences and post-traumatic stress disorder, and negative social and work experiences are associated with a higher risk of developing depression and/or chronic pain; personal attitudes such as catastrophizing and low self-efficacy are also risk factors of developing either or both states (O'Sullivan, 2004; Edwards et al., 2016). In a large genetic study, different pain phenotypes presented robust and positive genetic correlations with each other as well as with depression, suggesting common underlying genetic factors between pain and depression (Meng et al., 2020). Because it has a much higher incidence, approximately tenfold, than other mental disorders, evolutionary and pain psychologists have attempted to explain pain and depression in terms of behavioral adaptiveness. In this contest, Baliki and Apkarian (2015) support that nociception is essential to protect individuals from injury not only by inducing conscious pain and active avoidance behaviors but also by modulating automatic motor behaviors continuously and in the absence of overt pain. Similarly, a negative mood may be reconceptualized as a psychic pain that may be protective against environmental dangers in complex and hierarchical societies and promote healing; even persistent pain after an injury may have an adaptational value in that it favors survival after injuries that impair motor functions and increase vulnerability (Gałecki and Talarowska, 2017). In contrast, within the evolutionary framework, chronic pain beyond normal healing and chronic or relapsing depression are viewed as maladaptive processes which are maintained by neuropathological abnormalities.

\section{GLUTAMATE DRUGS}

\section{Neuroplasticity}

Neuroplasticity indicates the brain's ability to change over time and, more specifically, the ability of strengthening or weakening the synaptic signals between neurons in response to a variety of 
physiological stimuli such as behavioral, cognitive, and motor activities, as well as after pathological events such as painful or stressful conditions and neurological diseases (Lucassen et al., 2014; Pelletier et al., 2015). In chronic pain and depression, morphological and functional neuroplastic changes were found most pronounced in fronto-limbic regions (Mutso et al., 2012; Khan et al., 2014; Ezzati et al., 2019). The human prefrontal cortex is phylogenetically a recent brain area that matures late during development and is pivotal in the acquisition of motivational properties of different types of rewarding and aversive stimuli which include self-reference, self-appraisal, and emotion and mood control (Teffer and Semendeferi, 2012).

In chronic pain and depression, chronic exposure to stress is a common factor that may produce long-lasting changes (i.e., maladaptive neuroplasticity) in highly sensitive brain areas such as the prefrontal cortex and the hippocampus and in their functional connections, which may underlie the cognitive and behavioral impairments accompanying these conditions (Teffer and Semendeferi, 2012; Lucassen et al., 2014). For example, in comparison to healthy controls, a group of patients with chronic low back pain performing a simple visual attention task presented a reduced deactivation in regions of the default mode network; similarly, patients with a major depressive or a bipolar disorder while performing a $n$-back working memory task failed to deactivate the medial prefrontal cortex (Baliki et al., 2008; Rodríguez-Cano et al., 2017). The default mode, attention, and salience networks are all disrupted in pain and depression (Shao et al., 2018; van Ettinger-Veenstra et al., 2019). Conversely, the deep brain stimulation of the cingulate cortex relieved patients suffering from an intense neuropathic pain as well as patients with a severe treatment-resistant depression (Boccard et al., 2016; Zhang et al., 2018).

Treating pain improves depressive symptoms and vice versa (Skolasky et al., 2012; Rahman et al., 2020). Because the incidence of depressive and pain symptoms is increasing in parallel with the aging of the world population, it is particularly important to develop strategies that target both disorders to minimize polypharmacy and optimize therapeutic outcomes (Solhaug et al., 2012; Molton and Terrill, 2014). Although therapeutic options are available for chronic pain and depression, less than $50 \%$ of all patients treated for chronic pain report a clinically meaningful (i.e., $\geq 50 \%$ ) pain relief with current analgesic treatments, and only about $50-60 \%$ of patients with major depressive disorders achieved remission after an adequate course with conventional antidepressants. The efficacy of treatments of comorbid pain and depression has been less studied, but it is well known that these two conditions worsen each other's severity and therapeutic response.

Glutamate is the most abundant excitatory neurotransmitter in the central nervous system of adult mammals and has a major role in neuroplasticity (Henter et al., 2017; Pereira and Goudet, 2019). Glutamate acts through eight ionotropic and metabotropic receptor subtypes (mGluR1-mGluR8) that have been classified into three groups: Group I receptors (mGluR1 and mGluR5) are coupled to $\mathrm{G}_{\alpha \mathrm{q}}$ proteins and phospholipase $\mathrm{C}$ and are involved in central sensitization and pain chronification; Group II receptors (mGluR2/mGluR3) and Group III receptors
(mGluR4 and mGluR6-mGluR8) are coupled to $\mathrm{G}_{\alpha \mathrm{i} / \mathrm{o}}$ proteins and inhibit adenylate cyclase; their activation is effective against nociceptive and neuropathic pain (Zammataro et al., 2011; Henter et al., 2017; Pereira and Goudet, 2019).

Glutamate competitive and non-competitive ligands, binding to the same or to a different receptor site of the endogenous ligand, have been on development for at least three decades. Trials on stroke and traumatic brain injuries with competitive glutamate or glycine antagonists (i.e., selfotel, aptiganel, eliprodil, licostinel, and gavestinel) have failed (Ikonomidou and Turski, 2002). Recent trials with glutamate agents to treat pain and depression yielded promising but sometimes inconsistent results; non-selective glutamate modulators such as ALCAR and KET can still be of interest to glutamate research (Gould et al., 2019; Pereira and Goudet, 2019).

\section{ALCAR}

Acetyl-L-carnitine $\quad(\gamma$-trimethyl- $\beta$-acetylbutyrrobetaine $) \quad$ is an acetyl ester of carnitine, an endogenous molecule with pleiotropic biological and pharmacological activities on central and peripheral nervous systems (Chiechio et al., 2017). ALCAR has a key role in neuronal metabolism (i.e., $\beta$-oxidation, glycogen production, glucose utilization, and ammonia cycle), growth, plasticity, and regeneration; ALCAR is actively taken up by the brain and modulates the release of aminergic neurotransmitters and the biosynthesis and release of glutamate (Kuratsune et al., 2002; Tolu et al., 2002; Tanaka et al., 2003; Freo et al., 2009; Smeland et al., 2012; Chiechio et al., 2017; Wang et al., 2014; Burks et al., 2019). Exogenous ALCAR may increase neurogenesis in prefrontal-limbic areas via a selective upregulation of mGluR2 receptors, by acting as histone acetylator on transcription factors of the nuclear factor (NF)-kappa B family (Chiechio et al., 2006; Nasca et al., 2013).

In experiment animals, ALCAR is neuroprotective against hypoxia, nerve and spinal cord injury, and neurotoxins such as amphetamines and 1-methyl-4-phenyl-1,2,3,6tetrahydropyridine (Chiechio et al., 2017; Burks et al., 2019). In humans, low plasma levels of ALCAR have been associated with an increased vulnerability to chronic pain and depression. Specifically, circulating ALCAR was found to be reduced in patients with severe osteoarthritis pain that did not improve after a total joint replacement (Costello et al., 2020). ALCAR was found to be reduced also in the plasma and the brain of patients with chronic fatigue or major depressive disorder and, more markedly, when depression was severe, treatment resistant or associated with history of childhood trauma or neglect (Kuratsune et al., 2002; Nasca et al., 2018; Post, 2018; Pu et al., 2020).

Given its excellent, long-term safety profile, ALCAR has been studied in several neurological and psychiatric conditions, confirming a strong antineuropathic activity in toxic and traumatic painful neuropathies (Onofrj et al., 2013; Chiechio et al., 2017). Specifically, ALCAR improved the function of peripheral nerves by reducing sensory neuronal loss and by enhancing nerve regeneration and conduction velocity (Onofrj et al., 2013; Cruccu et al., 2017). Administration of ALCAR has consistently shown good tolerability and 
efficacy in dysthymic disorder and on depressive symptoms associated with fibromyalgia or minimal hepatic encephalopathy (Wang et al., 2014).

\section{Ketamine}

Ketamine is an arylcycloalkylamine structurally analogue to phencyclidine (PCP, angel dust), an approved anesthetic and the prototypical, non-competitive $N$-methyl-D-aspartate receptorglutamate (NMDA) antagonist.

In addition to NMDA antagonism, however, KET has a myriad of effects on neurotransmitters which include the following: increase of synaptic concentrations of acetylcholine in the spinal cortex, hippocampus, and neocortices; increase of glutamate, serotonin, and noradrenaline in the prefrontal cortex; increase of dopamine in the basal ganglia and neocortices; activation of synaptogenic $\alpha$-amino-3-hydroxy-5-methyl-4isoxazolepropionic acid (AMPA) receptors; and activation of synaptogenic intracellular signaling, including mammalian target of rapamycin complex (TORC1) (Freo and Ori, 2002b, 2003; Cohen et al., 2018). Behaviorally, KET has almost unique, dose-dependent effects on the central nervous system. Different from most general anesthetics, at high, anesthetic doses, KET and few other congeners produce a "dissociative anesthesia" during which patients may appear awake and maintain spontaneous eye movements and respiratory drive although they are relatively insensitive to sensory stimulation (Cohen et al., 2018). At lower subanesthetic doses, KET promotes arousal from anesthesia and has strong antidepressant and analgesic activities (Hambrecht-Wiedbusch et al., 2017; Cohen et al., 2018). After a low intravenous dose of KET $(0.5 \mathrm{mg} / \mathrm{kg})$, most patients with a major depressive disorder reported a very fast, within hours, improvement of depressive symptoms that lasted for 7-10 days (Cohen et al., 2018). The antidepressant effects of KET were replicated in patients with treatment-resistant or bipolar depression, suggesting that KET may be effective on a wider range of depressed patients (Romeo et al., 2015).

In addition, low-dose KET has been beneficial on large numbers of patients suffering from oncological and nononcological pain (Cohen et al., 2018; Orhurhu et al., 2019). The consensus guidelines recently elaborated by the American Society of Regional Anesthesia and Pain Medicine, the American Academy of Pain Medicine, and the American Society of Anesthesiologists support the use of KET for chronic pain, but with different degrees of evidence for different conditions and dose ranges (Cohen et al., 2018). Adverse events of KET were similar to those of placebo, with higher dosages and more frequent infusions being associated with greater risks (Cohen et al., 2018). However, not all authors agree and dismiss KET adverse events as anecdotal. In clinical practice, using KET for chronic pain or depression is still limited by intravenous administration and its potential neurotoxic and toxic effects (Jevtovic-Todorovic et al., 2001; Liao et al., 2010; Orhurhu et al., 2020). However, intranasal and oral administration as well as the discovery of antidepressant activity and lower psychotomimetic effect of isomers and metabolites of KET may foster a wider and longer-term clinical use of KET in the future (Zanos et al., 2016). Because $\mathrm{S}(+)$ KET has higher affinity for NMDA receptors than
$\mathrm{R}(-)$ KET, $\mathrm{S}(+)$ KET has been developed and later approved by the Food and Drug Administration as a clinical antidepressant (Hashimoto, 2019). However, in animal models of depression, $\mathrm{R}(-)$ KET has shown longer-lasting antidepressant effects and lesser adverse effects than $\mathrm{S}(+) \mathrm{KET}$ and is currently being investigated as a promising antidepressant (Hashimoto, 2019).

\section{CEREBRAL METABOLISM STUDIES}

The regional cerebral metabolic rates for glucose (rCMRglc) were measured using the quantitative autoradiographic $\left[{ }^{14} \mathrm{C}\right] 2$ deoxy-D-glucose technique in groups of five to seven male, Fischer-344, conscious rats at $30 \mathrm{~min}$ after IV administration of saline or ALCAR $250-750 \mathrm{mg} / \mathrm{kg}$ and at $20 \mathrm{~min}$ after IV saline or KET $20 \mathrm{mg} / \mathrm{kg}$ (Ori et al., 2002; Freo and Ori, 2004). The $\left[{ }^{14} \mathrm{C}\right] 2$-deoxy-D-glucose procedure has been detailed previously (Freo and Ori, 2002a, 2004, 2009).

Acetyl-L-carnitine dose-dependently increased rCMRglc in the prefrontal, cingulate, and somatosensory cortices, in the cortical amygdala and in the accumbens, diagonal band, dorsal raphe, and locus coeruleus nuclei (ANOVA and unpaired $t$-test, $P<0.05)$ (Figure 1; Ori et al., 2002). Acetate and carnitine alone had no effect on cerebral metabolism, indicating that rCMRglc increases by ALCAR are independent from its effects on mitochondrial metabolism (Ori et al., 2002). KET $[S, R( \pm)$ ketamine] increased rCMRglc similarly to ALCAR in cortical areas, to a lesser extent in serotoninergic raphe nuclei and to a much greater extent in hippocampal regions and dopaminergic nuclei (average percentage increase $32.2 \pm 11.4$ vs. $20.0 \pm 23.0$; $P<0.01$ ) (Freo and Ori, 2004). Using functional magnetic resonance imaging in paralyzed, mechanically ventilated rats, Masaki and coworkers reported that $S, R( \pm) K E T 10 \mathrm{mg} / \mathrm{kg}$ and $\mathrm{S}(+) \mathrm{KET} 10 \mathrm{mg} / \mathrm{kg}$ increased the regional cerebral blood flow signal in the basal ganglia and cortical regions in a similar fashion to that in MK801 (Masaki et al., 2019); in contrast, the same dose of $\mathrm{R}(-)$ KET produced no noticeable behavioral change and a widespread decrease of regional cerebral blood flow (Freo and Ori, 2004; Masaki et al., 2019). In GluN2D-knockout mice, KET failed to increase the $\left[{ }^{14} \mathrm{C}\right]-2$-deoxy-D-glucose uptake as well as the cortical gamma-band power, suggesting that prefrontal cortical activations are mediated by mGluR2 receptors (Sapkota et al., 2016). Furthermore, in humans, KET increased the $\left[{ }^{18} \mathrm{~F}\right]$-fluorodeoxy-D-glucose uptake in the prefrontal cortex in a correlative fashion to post-treatment antidepressant effects (Li et al., 2016). Finally, the antidepressant effects of KET continuing beyond its pharmacokinetic half-life was associated with persistent activation of the frontal supplementary motor and cingulate cortices (Chen et al., 2018).

While the rCMRglc effects of KET were similar to those of other non-competitive NMDA antagonists, they differ markedly from the small rCMRglc changes induced by competitive NMDA receptor antagonists (i.e., AP7, CGP39551, CPP, and CGS19755), which have demonstrated relatively modest antidepressant effects and to actually counteract KET-induced dopamine activations (French, 1992; Sharkey et al., 1996; Iadarola et al., 2015). Preclinical and (Freo and Ori, 2002a,b) human studies have reported 


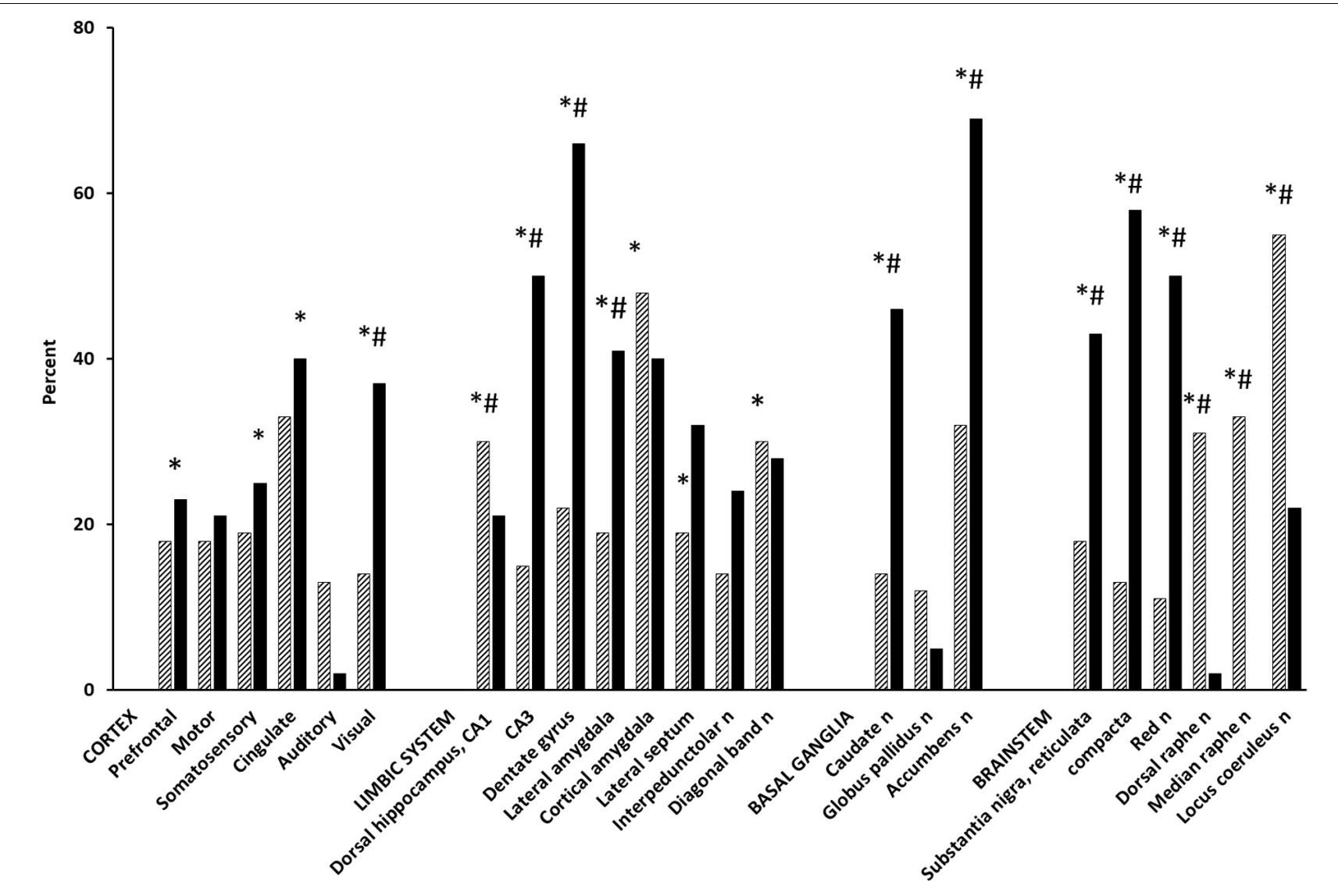

FIGURE 1 | Effect of ALCAR and KET on rCMRglc. Bars are mean rCMRglc differences (percent) from saline controls in groups of 5-7 Fischer-344, male rats at 30 min after IV administration of ALCAR 500 mg (hatched) and 20 min after IV KET 20 mg (solid). ALCAR difference from saline control: *P < 0.05; ALCAR difference from KET: ${ }^{\#} P<0.05$.

abnormalities of glutamatergic systems in depression (JiménezSánchez et al., 2016); conversely, enhancement of glutamate neurotransmission in the prefrontal cortex is considered necessary and sufficient for the antidepressant properties of glutamate drugs (Fukumoto et al., 2016; Highland et al., 2019). However, ALCAR and KET differ in their mechanisms of action and can lead to prefrontal activation in two different manners: ALCAR may do so directly via upregulation of mGluR2 receptors, KET may act indirectly via an NMDA antagonism on GABA inhibitory neurons, and the subsequent disinhibition of pyramidal cortical neurons (Moghaddam et al., 1997). Enhanced AMPA/glutamate transmission by KET stimulates, in turn, release of adrenaline and serotonin, which may contribute to KET antidepressant effects (Fukumoto et al., 2016; Jiménez-Sánchez et al., 2016).

Compared to ALCAR, KET determined greater rCMRglc increases in dopaminergic nuclei (i.e., accumbens and substantia nigra, pars reticulata and compacta, nuclei: 233, 138, and $346 \%$, respectively, $P<0.01$ ) and in hippocampal areas (i.e., dorsal $\mathrm{CA}_{3}$ and dentate gyrus: 233 and 200\%, respectively, $P<0.01$ ), which are among the largest metabolic activations ever reported (Sharkey et al., 1996). However, they are consistent with the marked increases KET elicits also on electrical activity in the ventral tegmental area, extracellular concentrations of dopamine in the nucleus accumbens and prefrontal cortex, and hyperlocomotion by the dopamine $\mathrm{D}_{2 / 3}$ receptor agonist quinpirole (Witkin et al., 2016). KET dopaminergic activations were prevented by dopaminergic neuroleptics and an AMPA receptor antagonist, indicating AMPA-dependent effects (Duncan et al., 2003; Witkin et al., 2016). While the role of dopaminergic and glutamatergic activations in KET antidepressant actions remains questionable, the large rCMRglc increase KET induces in mesolimbic areas likely reflects dopamine "surges" that mediate natural and drug rewards and, possibly, the abuse liability of KET (Kokkinou et al., 2018; Volkow et al., 2019). In contrast, ALCAR increases much less dopamine release and rCMRglc; although it is faster than conventional selective serotonin and/or norepinephrine reuptake inhibitor and tricyclic antidepressants, ALCAR is a less potent and slower antidepressant than KET and is devoid of abuse risk (Tolu et al., 2002; Romeo et al., 2015; Chiechio et al., 2017).

In experiment animals, KET has potential neuroprotective properties in stroke, neurotrauma, subarachnoid hemorrhage, and status epilepticus; however, KET has been reported to cause also some worrisome neurotoxic damage, which, interestingly, can be counteracted by ALCAR (Jevtovic-Todorovic et al., 2001; 
Liao et al., 2010; Robinson et al., 2016; Bell, 2017; Orhurhu et al., 2020).

Acetyl-L-carnitine increased rCMRglc to a similar extent in most brain areas in young and aged rats and to a larger extent in the limbic regions of aged rats (Freo et al., 2009). Following its chronic administration, ALCAR determined larger rCMRglc increases in hippocampal areas, which are crucial to attention and memory functions (Freo et al., 2009). Because ALCAR is endowed with cholinomimetic properties, its positive effects on attention and memory were ascribed to ALCAR cholinergic agonism (Battistin et al., 1989; Jeong et al., 2017). However, as the limbic regions are electrically and metabolically hyporesponsive to acute cholinergic muscarinic stimulation and to chronic cholinergic treatment, a noncholinergic mechanism for memory-enhancing effects of ALCAR is likely (Freo et al., 2009). During aging, the glutamate neurotransmission undergoes complex changes within the hippocampus, which include increases of glutamate-induced phosphoinositol hydrolysis, of densities of glutamate receptors (i.e., mGluR2, mGluR3, and mGluR5) and of their mRNAs, all of which have been interpreted as compensatory for agerelated alteration of glutamate neurotransmission (Griego and Galván, 2020). The aging cognitive decline has been associated with weakened synaptic strength in prefrontal and hippocampal regions. Interestingly, riluzole, a glutamate release inhibitor and glutamate antagonist, was shown to increase glutamatergic activity in the hippocampus, preventing thus cognitive decline during aging (Pereira et al., 2014). Hence, ALCAR may also have a positive effect on cognitive functions by activating the hippocampal glutamatergic mechanisms.

\section{CLINICAL STUDIES}

\section{Effects of ALCAR on Chronic Pain}

Chronic pain and depression often coexist, requiring frequent or continuous treatments (Freo et al., 2019a). Multi-pathologies and multi-therapies make it challenging especially in the elderly and frail population. In comorbid chronic pain and depression, ALCAR may be useful because of its analgesic and antidepressant properties and high long-term tolerability (Chiechio et al., 2017).

We investigated the effects of ALCAR in painful neuropathies and radiculopathies that were unresponsive or poorly responsive (i.e., $\leq 30 \%$ pain relief) to previous therapies in 28 patients (17 females and 11 males; age $66.4 \pm 10.1$ years; pain duration $16 \pm 21$ months) (Freo et al., 2019a). The primary outcome was pain intensity after a 4-month treatment with ALCAR $500 \mathrm{mg}$ BID that was given initially IM for an average of $57 \pm 9$ days and then PO. Patients were assessed for the 24$\mathrm{h}$ average pain with a $0-10$ numerical rating scale (NRS) (pain rating, $0=$ no pain, $1-3=$ mild, $4-6=$ moderate, and $7-$ 10 = severe pain), for neuropathic pain symptoms with the painDETECT questionnaire $[<12=$ negative (nociceptive pain), 13-18 = uncertain (mixed pain), $\geq 19=$ positive (neuropathic pain)], for depressive symptoms with the Hospital Anxiety and Depression Scale (HADS) $(<7=$ no depression, $8-10=$ mild, $11-$ $15=$ moderate, and 16-21 = severe depression), and for quality of life with the 12-item Short Form Health Survey (SF-12), physical and mental components (Freo et al., 2019a,b).

At baseline, all patients reported a moderate-to-severe, 24-h average pain (NRS $\geq 4 / 10$ ), $60 \%$ of patients reported symptoms of a mild-to-moderate depression (HADS $\geq 8$ ), and $57 \%$ had a positive painDETECT score $(\geq 12)$ for neuropathic pain (Freo et al., 2019a). The 4-month treatment with ALCAR was associated with a reduction of pain and depression (Figure 2). Pain intensity significantly improved from baseline to month 1 of treatment (pain NRS from $7.4 \pm 1.5$ to $5.6 \pm 1.7$; means \pm standard deviation, Kruskal-Wallis and Wilcoxon's test, $P<0.01$ ) and depressive symptoms improved already at week 2 of treatment (HADS scores from $8.8 \pm 4.4$ to $6.1 \pm 3.4$, $P<0.01$ ) (Figure 2; Freo et al., 2019a). Compared to baseline, at month 4 outcome, a moderate (30-49\%) pain improvement was observed in 11 patients and a substantial $(\geq 50 \%)$ improvement in 8 patients. The painDETECT score for neuropathic pain decreased from baseline to month 4 outcome from $12.6 \pm 6.0$ to $5.0 \pm 0.9(P<0.01)$; the SF-12 mental component increased from $44.1 \pm 4.5$ to $53.5 \pm 5.1(P<0.01)$ and the SF-12 physical component from $35.3 \pm 3.5$ to $39.4 \pm 5.2$ (not significant). Five patients discontinued treatment because of lack of efficacy or unwillingness to continue treatment; no adverse effect was recorded (Freo et al., 2019a).

Reportedly, ALCAR improved pain and nerve function in experimental and clinical neuropathies of different etiologies with therapeutic effects being ascribed mainly to ALCAR neuroprotective and neuroregenerative properties ( $\mathrm{Li}$ et al., 2015). However, although in peripheral neuropathies, depression is common and noradrenaline-serotonin reuptake inhibitor and tricyclic antidepressants are first-line treatments, depressive symptoms are not always measured. Pain and depression have a biunivocal relation with worsening or improvement in one variable predicting subsequent changes in severity of the other (Kroenke et al., 2011; D’Amato et al., 2016). As such, rapidacting antidepressant and analgesic drugs have been a major breakthrough (Chiechio et al., 2017). In our patients, ALCAR improved depressive symptoms earlier than pain symptoms, suggesting that the antidepressant activity of ALCAR may anticipate and contribute to its analgesic properties.

Chronic neuropathic pain and depression are age-dependent, highly comorbid disorders that complicate courses and outcomes (Dworkin et al., 2003; Brouwer et al., 2015; Hanewinckel et al., 2016; Freo et al., 2019b). Therapeutic responses are often poor and limited by concurrent therapies. The elderly population is at increased risk for adverse events from antidepressants and anticonvulsants that may worsen stability, balance, and cognition (Dworkin et al., 2003; Brouwer et al., 2015; Hanewinckel et al., 2016). Because of its high tolerability and the positive effect it has on pain, depression, and cognition, ALCAR should be in the therapeutic armamentarium for treating comorbid pain and depression, especially in the elderly population.

\section{Effects of KET on Post-operative Pain}

Almost unique among general anesthetics, the NMDA antagonist KET has anesthetic properties with low cardiovascular and respiratory depression (Cohen et al., 2018). KET is also clinically 

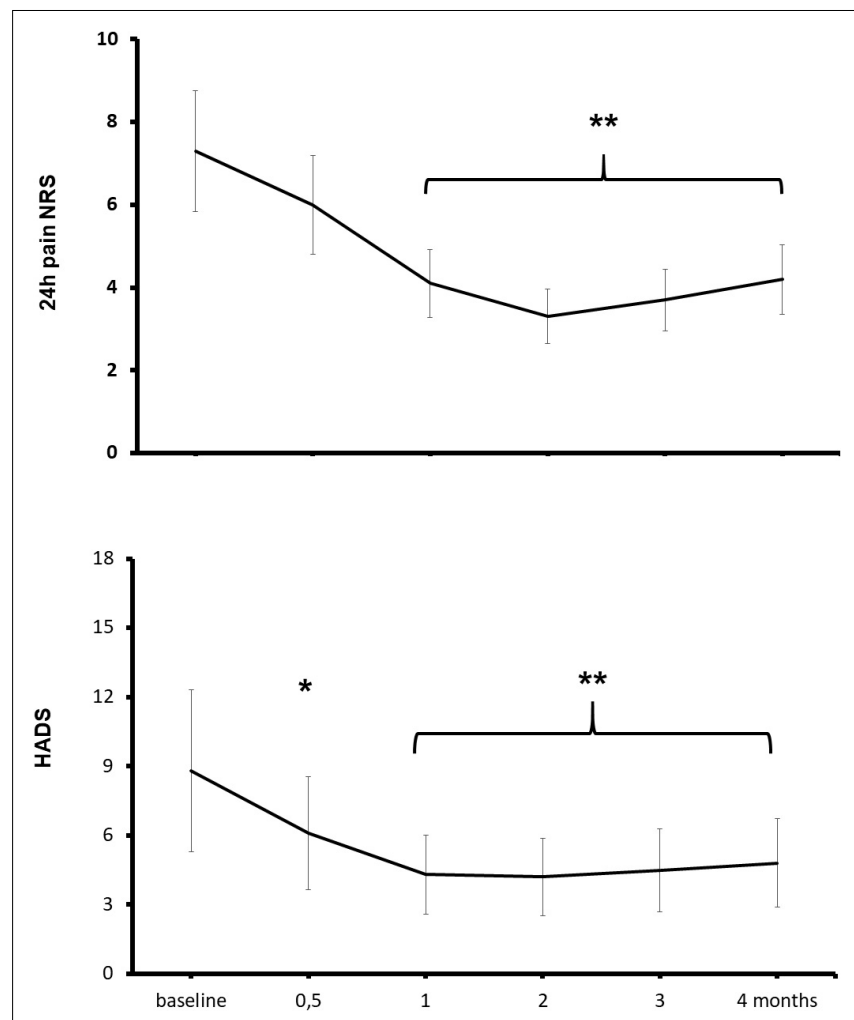

FIGURE 2 | Effects of ALCAR on chronic pain and depression. Points are means \pm standard deviation of 24-h average pain NRS scores (above) and depression HADS scores (below) from pre-treatment baseline to month 4 treatment in 28 patients receiving ALCAR $500 \mathrm{mg}$ BID IM/PO for chronic neuropathy or radiculopathy pain. Significantly different from baseline: ${ }^{\star} P<0.05 ;{ }^{\star \star} P<0.01$.

attractive because it has strong analgesic and antidepressant activities and may prevent central sensitization and hyperalgesia (Freo and Ori, 2003; Ori et al., 2003; García-Henares et al., 2018). Hence, KET is of interest for patients prone to anesthesia-induced respiratory impairment or suffering from chronic pain and/or depression or, more, for patients presenting with all these clinical features such as the morbidly obese (Freo and Ori, 2003; Ori et al., 2003; Carron et al., 2012; García-Henares et al., 2018).

In fact, overweight and obesity are frequently associated with an obstructive apnea syndrome and/or to a depressive disorder that places patients at risk, respectively, of post-operative critical events and of post-operative complications and prolonged stay (Luppino et al., 2010; Ghoneim and O'Hara, 2016; Subramani et al., 2017; Nijland et al., 2020). Obesity is associated with higher rates of chronic pain and higher scores of post-operative pain, which are both challenging to treat in this patient population (Belcaid and Eipe, 2019; Mills et al., 2019). As opioids may induce ventilatory impairment, multimodal opioid- and muscle relaxant-sparing techniques are being investigated to improve the safety of analgesia in obese patients; in this regard, KET may present specific advantages (Ori et al., 2003; Dalsasso et al., 2005; Freo et al., 2011; Carron et al., 2012; García-Henares et al., 2018; Aronsohn et al., 2019).
The effects of KET as the main anesthetic agent were determined in 500 patients (172 males and 328 females, ASA III, age $53.9 \pm 12.2$ years, weight $76.1 \pm 22.5 \mathrm{~kg}$ ) undergoing an opioid-free anesthesia for day surgery including breast surgery, laparoscopy, superficial excision of minor lesions, thoracoscopy, appendectomy, and proctology (Dalsasso et al., 2005). At induction, patients received IV midazolam $0.03-0.05 \mathrm{mg} / \mathrm{kg}$, clonidine $150 \mu \mathrm{g}$, and KET $0.4 \mathrm{mg} / \mathrm{kg}$; the latter was repeated as needed during surgery (mean total dose $0.6 \pm 0.2 \mathrm{mg} / \mathrm{kg}$ ). Anesthesia was maintained with nitrous oxide and sevoflurane. Seventy-four percent of patients were eligible to discharge from the operating theater by $30 \mathrm{~min}$, and all patients were dischargeable by $1 \mathrm{~h}$. Patients did not complain of hallucinations, while presenting a high rate of satisfaction at the Iowa Satisfaction with Anesthesia Scale (Dalsasso et al., 2005).

The post-operative effects of KET were assessed in 41 obese patients (26 females and 15 males; age $42.7 \pm 10.7$ years; body mass index $44.5 \pm 7.2$ ) undergoing laparoscopic gastric banding or sleeve gastrectomy with the primary outcomes being post-operative pain and depression (Freo, 2020). All patients were pre-medicated with midazolam and induced with IV propofol $1.5 \mathrm{mg} / \mathrm{kg}$ and fentanyl $1-2 \mu \mathrm{g} / \mathrm{kg}$ and maintained with sevoflurane 1-2\%; patients were randomized to receive at induction either saline or $\mathrm{KET}[\mathrm{S}, \mathrm{R}( \pm)$ ketamine $0.5 \mathrm{mg} / \mathrm{kg}$ by ideal body weight]. Baseline demographic features (i.e., age, education, body mass index, comorbidities, and medical therapies), times of anesthesia and surgery, and average propofol dosages were similar between groups; average fentanyl dosage was higher in the saline control than in the KET group (i.e., $341 \pm 109$ and $192 \pm 67 \mathrm{mg}, P<0.01$ ) (Freo, 2020).

At pre-operative baseline, in the control and the KET groups, seven and eight patients reported moderate-to-severe pain (NRS $\geq 4 / 10$ ), and 9 and 10 patients presented mild-to-moderate depressive symptoms in the Hamilton Depression Rating Scaling (HAMD), respectively (Freo, 2020). Pain scores were significantly lower at post-operative hours 6 and 12 in KET-treated patients than in controls and then subsided in both groups (Figure 3). Pain improvement was less in non-depressed than depressed patients (mean intergroup difference at post-operative day 1 , -33 and $-51 \%, P<0.05$ ) (Freo, 2020). HAMD scores were significantly lower in the KET-pre-treated patients at the postoperative days 1 and 3 (HAMD scores in saline and KET groups at baseline: $6.7 \pm 5.7$ and $7.1 \pm 5.7$; at post-operative day $1: 6.7 \pm 5.7$ and $3.4 \pm 2.6$; at post-operative day $3: 7.0 \pm 5.6$ and $3.7 \pm 2.9$; Friedman's and Mann-Whitney $U$ tests, $P<0.01$ ) (Figure 4; Freo, 2020).

A recent Cochrane meta-analysis review concluded that perioperative intravenous KET reduces post-operative pain and nausea and analgesic consumption (Brinck et al., 2017); however, not all studies are consistent with these findings. In a recent randomized controlled study (RCT) on 100 obese patients, of whom 22 with history of depression and 13 with history of chronic pain, undergoing laparoscopic gastric bypass or gastrectomy, post-operative infusion of KET $(0.4 \mathrm{mg} / \mathrm{kg}$, ideal body weight) was not superior to placebo on postoperative pain and mood assessed with a pain Visual Analogue 


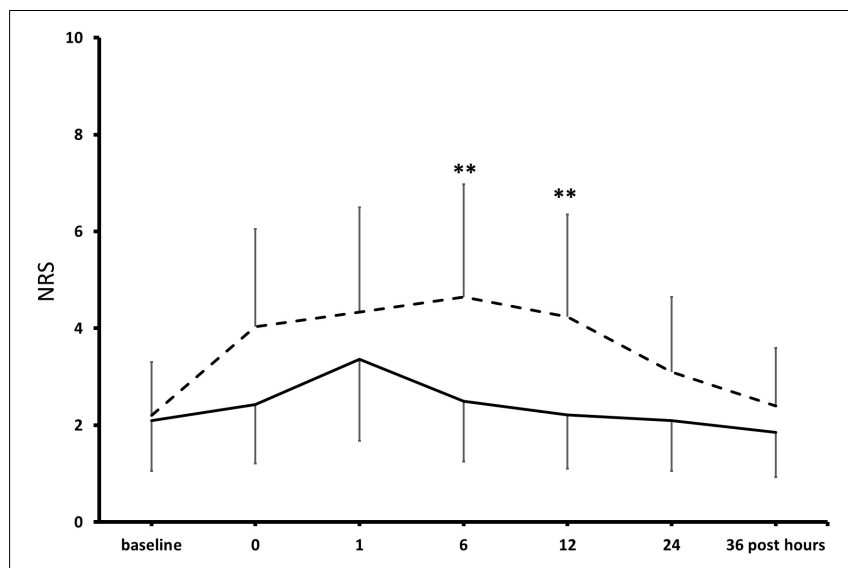

FIGURE 3 | Effects of KET on post-operative pain in obese bariatric patients. Points are means \pm standard deviations of NRS scores of pain in the first $36 \mathrm{~h}$ after bariatric surgery in 41 obese patients who had received either saline (broken line) or KET $0.5 \mathrm{mg} / \mathrm{kg}$ (continuous line) at induction of anesthesia. Significantly different from saline controls: ${ }^{\star \star} P<0.01$.

Scale, the Beck Depression Inventory and the MontgomeryAsberg Depression Rating Scale; KET, however, improved the affective and the total score of the short-form McGill Pain Questionnaire starting on post-operative day 2 (Wang et al., 2019). In the PODCAST multicenter RCT on 672 older adults (i.e., $>60$ years) undergoing cardiac and noncardiac surgery, pre-incisional KET $(0.5$ or $1 \mathrm{mg} / \mathrm{kg})$ did not decrease post-operative pain, delirium, or depressed mood (Avidan et al., 2017).

Most negative studies focused on post-operative pain. Analgesic effects of KET are considered use dependent: the worst the pain, the more efficient KET will be as analgesic (Robu and Lavand'homme, 2019). The same may hold true for its antidepressant effect. KET has a plasma half-life of $2.3 \pm 0.5 \mathrm{~h}$ with a duration of action of IV bolus of 5-10 min (Cohen et al., 2018). KET has a rapid and potent antidepressant effect that peaks at 24-48 $\mathrm{h}$ after administration and could have a larger impact on patients with mood disorders (Cohen et al., 2018). Consistently, Kudoh et al. (2002) reported that KET significantly improved mood and pain on post-operative day 1 in depressed patients undergoing orthopedic surgery. In a second double-blind RCT, KET $0.5 \mathrm{mg} / \mathrm{kg}$ IV bolus followed by a $30 \mathrm{~min}$ infusion of $0.25 \mathrm{mg} / \mathrm{kg} / \mathrm{h}$ increased mood and serum brain-derived neurotrophic factor, which is a marker of major depressive disorders and treatment response (Jiang et al., 2016). It is therefore possible that the analgesic effect of KET is contributed at least in part by its antidepressant activities. In our sample, 15 patients (37\%) had at least a mild-to-moderate depression, and nine patients were on chronic antidepressant therapy; large-cohort studies indicated that the prevalence of subclinical depression ranges from 1 to $17 \%$ (Heo et al., 2006), which suggests that obese patients with mood disorders may especially benefit from KET treatment.

Ketamine is endowed with a peculiar profile with multiple pharmacological activities that may result from different

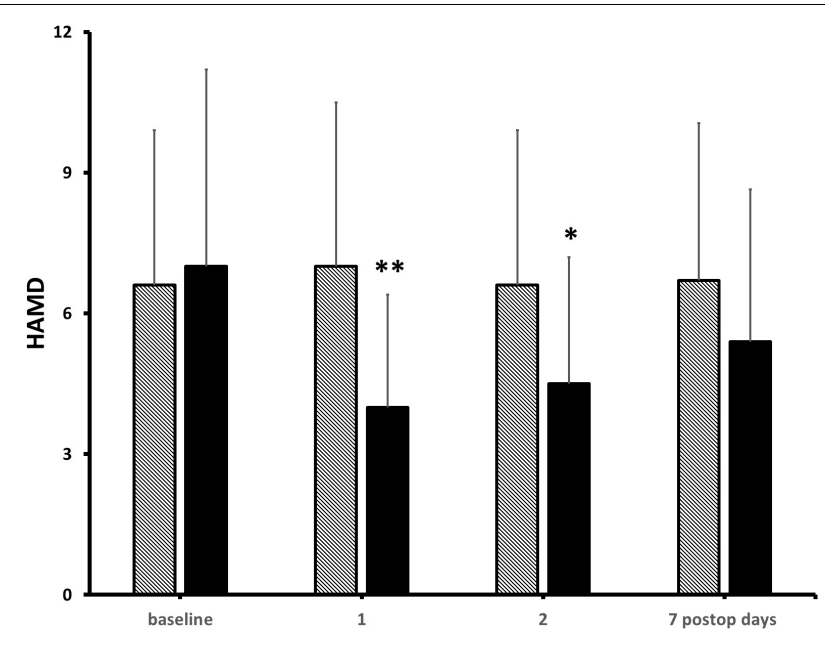

FIGURE 4 | Effects of KET on depression in obese bariatric patients. Columns are means \pm standard deviations of HAMD scores from baseline to post-operative day 7 in 41 bariatric patients who had received either saline (hatched columns) or KET $0.5 \mathrm{mg} / \mathrm{kg}$ (solid columns) at induction of anesthesia. Significantly different from saline controls: ${ }^{*} P<0.05 ;{ }^{* *} P<0.01$.

underlying mechanisms. Other NMDA antagonists (i.e., MK801 and memantine) do not have the same anesthetic, analgesic, and antidepressant effects of KET, leaving open the question of its mechanisms of action (Kelland et al., 1993; Gould et al., 2019; Robu and Lavand'homme, 2019). Besides the glutamate system, KET interacts with several other neurotransmitter systems (Jelen et al., 2020). For example, the administration of the insulin growth factor small-interfering RNA blocks KET antidepressant effects in the mouse learned helplessness model of depression (Grieco et al., 2016). In rodents, activation of AMPA receptors by the KET metabolite (2R,6R)-hydroxynorketamine has initially been thought essential to replicate KET antidepressant effects while administration of 2,3-dihydroxy-6-nitro-7-sulfamoylbenzo[f]quinoxaline-2,3-dione (NBQX), an AMPA receptor antagonist, blocks KET effects (Zanos et al., 2016). However, in subsequent investigations in rodent models of depression, (2R,6R)-hydroxynorketamine did not exhibit antidepressant-like effects and increased aggressive behavior (Yang et al., 2019). The brain-derived neurotrophic factor (BDNF) and its receptor, tyrosine kinase receptor B (TrkB), are essential and common mechanisms for the antidepressant effects of both the parent molecules of ketamines [i.e., $\mathrm{S}, \mathrm{R}( \pm)$ ketamine, $\mathrm{S}(+)$ ketamine, and $\mathrm{R}(-)$ ketamine] and their active metabolites [i.e., $(2 \mathrm{R}, 6 \mathrm{R})-$ hydroxynorketamine and of $\mathrm{S}(+)$ norketamine] (Yang et al., 2019). In patients with treatment-resistant depression, naltrexone $50 \mathrm{mg}$ blocked the antidepressant but not the dissociative effects of KET, suggesting that the opioid system may also be required for KET antidepressant activities (Williams et al., 2018). Other works, however, have shown that naltrexone pre-treatment did not affect the antidepressant activities of KET in depressed individuals (Marton et al., 2019; Yoon et al., 2019; Zhang and Hashimoto, 2019). 


\section{ALCAR AND KET AS GLUTAMATE DRUGS FOR PAIN AND DEPRESSION}

The excitatory actions of glutamate in the central nervous system have been recognized in the early 1950s (Curtis and Watkins, 1960). Since the discovery of neurotoxic effects of massive glutamate release, glutamate antagonists have been trialed in massive neuronal damage (i.e., stroke and brain and spinal cord trauma), with disappointing results (Ikonomidou and Turski, 2002). Later, it was shown that glutamate is actually essential to physiological neuroplasticity underlying learning and memory, as well recovery from brain stroke or trauma (Ikonomidou and Turski, 2002).

The report of the fast antidepressant effects of KET, a non-selective glutamate agent, fostered interest in the role of glutamate in specific neurological functions (Henter et al., 2017; Pereira and Goudet, 2019). Reportedly, glutamate is involved in maladaptive neuroplastic processes contributing to generation and maintenance of pain and mood disorders (Riggs and Gould, 2021). Frontal areas are critical for topdown cognitive modulation of pain and pain-related emotions (Thompson and Neugebauer, 2019). A lower level of frontal activity has been linked to higher pain and low mood, and conversely, an increased frontal activity has been linked to analgesic and antidepressant effects (Thompson and Neugebauer, 2019). Furthermore, glutamate concentrations are reduced in frontal areas in experimental and clinical pain (Thompson and Neugebauer, 2019), and a frontal glutamatergic dysfunction has been implicated in depression as well (Moriguchi et al., 2019). Therefore, modulation of glutamate neurotransmission is a current research target for pain and depression (Pereira and Goudet, 2019; Riggs and Gould, 2021).

The number of glutamate-receptor-selective agents has been fast growing, but the clinical safety still remains an issue for most new agents (Henter et al., 2017; Pereira and Goudet, 2019). Also, more generally, development of non-glutamate drugs for pain and depression has been plagued by failures in advanced human trials. As a consequence, older glutamate drugs are being reassessed.

Acetyl-L-carnitine and KET are non-selective, clinical glutamate modulators which have been shown to improve pain

\section{REFERENCES}

Aronsohn, J., Orner, G., Palleschi, G., and Gerasimov, M. (2019). Opioid-free total intravenous anesthesia with ketamine as part of an enhanced recovery protocol for bariatric surgery patients with sleep disordered breathing. J. Clin. Anesth. 52, 65-66. doi: 10.1016/j.jclinane.2018.09.014

Avidan, M. S., Maybrier, H. R., Abdallah, A. B., Jacobsohn, E., Vlisides, P. E., Pryor, K. O., et al. (2017). Intraoperative ketamine for prevention of postoperative delirium or pain after major surgery in older adults: an international, multicentre, double-blind, randomised clinical trial. Lancet (Lond. Engl.) 390, 267-275. doi: 10.1016/S0140-6736(17)31467-8

Bair, M. J., Robinson, R. L., Katon, W., and Kroenke, K. (2003). Depression and pain comorbidity: aliterature review. Arch. Intern. Med. 10, 2433-2445. doi: 10.1001/archinte.163.20.2433

Baliki, M. N., and Apkarian, A. V. (2015). Nociception, pain, negative moods, and behavior selection. Neuron 87, 474-491. doi: 10.1016/j.neuron.2015.06.005 and depressed mood in different experimental and clinical settings; they share the common properties of increasing brain glutamate concentration and neurotransmission and of activating rCMRglc in frontal areas and subcortical aminergic nuclei (Toth et al., 1993; Moghaddam et al., 1997; Fukumoto et al., 2016; Jiménez-Sánchez et al., 2016). These findings are consistent with frontal and brainstem activations occurring during opioid, placebo (Petrovic et al., 2002), and other types of analgesia and in individuals resilient to depression (Ong et al., 2019; Fischer et al., 2021). Prefrontal and frontal cortices are pivotal components of the "pain matrix" and of the frontolimbic, frontostriatal, and default-mode networks that regulate pain perception, emotionally driven behaviors, and attention allocation (Li et al., 2018; Ong et al., 2019). A prefrontal dysfunction/hypofunction has been associated with abnormal pain processing and with loss of pleasure, motivational energy, cognitive abilities, and speed. In contrast, increased frontal activation and/or normalization of abnormal connectivity have been associated with improvement of pain and of sad mood (Li et al., 2018; Ong et al., 2019). ALCAR and KET also activated brainstem nuclei (locus coeruleus, diagonal band, and raphe nuclei) which send aminergic projections to cortical areas and spinal dorsal horns that are involved in pain and mood control (Freo et al., 2010; Khan and Stroman, 2015).

Altogether, the findings indicate that non-selective, clinical glutamate modulators such as ALCAR and KET can still provide therapeutic benefits and generate hypotheses on glutamate drug actions in neuropsychiatric conditions.

\section{AUTHOR CONTRIBUTIONS}

UF and GZ contributed to the conception and design of the study and wrote sections of the manuscript. UF wrote the first draft of the manuscript. All authors revised, read, and approved the submitted version.

\section{FUNDING}

This research was supported by departmental funds only.

Baliki, M. N., Geha, P. Y., Apkarian, A. V., and Chialvo, D. R. (2008). Beyond feeling: chronic pain hurts the brain, disrupting the default-mode network dynamics. J. Neurosci. 28, 1398-1403. doi: 10.1523/jneurosci.4123-07.2008

Battistin, L., Pizzolato, G., Dam, M., Da Col, C., Perlotto, N., Saitta, B., et al. (1989). Single-photon emission computed tomography studies with 99mTc-hexamethylpropyleneamine oxime in dementia: effects of acute administration of L-acetylcarnitine. Eur. Neurol. 29, 261-265. doi: 10.1159/ 000116423

Belcaid, I., and Eipe, N. (2019). Perioperative pain management in morbid obesity. Drugs 79, 1163-1175. doi: 10.1007/s40265-019-01156-3

Bell, J. D. (2017). In vogue: ketamine for neuroprotection in acute neurologic injury. Anesth. Analg. 124, 1237-1243. doi: 10.1213/ANE.0000000000001856

Boccard, S. G. J., Prangnell, S. J., Pycroft, L., Cheeran, B., Moir, L., Pereira, E. A. C., et al. (2016). Long-term results of deep brain stimulation of the anterior cingulate cortex for neuropathic pain. World Neurosurg. 106, 625-637. doi: 10.1016/j.wneu.2017.06.173 
Brinck, E. C., Tiippana, E., Heesen, M., Bell, R. F., Straube, S., Moore, R. A., et al. (2018). Perioperative intravenous ketamine for acute postoperative pain in adults. Cochr. Datab. Syst. Rev. 12:CD012033. doi: 10.1002/14651858. CD012033.pub4

Brouwer, B. A., de Greef, B. T., Hoeijmakers, J. G., Geerts, M., van Kleef, M., Merkies, I. S., et al. (2015). Neuropathic pain due to small fiber neuropathy in aging: current management and future prospects. Drugs Aging 32, 611-621. doi: 10.1007/s40266-015-0283-8

Burks, S., Raymick, J., Robinson, B., Hanig, J., and Sarkar, S. (2019). Neuroprotective effects of acetyl-l-carnitine (ALC) in a chronic MPTP-induced Parkinson's disease mouse model: endothelial and microglial effects. Neurosci. Lett. 703, 86-95. doi: 10.1016/j.neulet.2019.03.015

Carron, M., Veronese, S., Gomiero, W., Foletto, M., Nitti, D., Ori, C., et al. (2012). Hemodynamic and hormonal stress responses to endotracheal tube and ProSeal laryngeal mask airway ${ }^{\mathrm{TM}}$ for laparoscopic gastric banding. Anesthesiology 117, 309-320. doi: 10.1097/aln.0b013ef31825b6a80

Chen, M. H., Li, C. T., Lin, W. C., Hong, C. J., Tu, P. C., and Bai, Y. M. (2018). Persistent antidepressant effect of low-dose ketamine and activation in the supplementary motor area and anterior cingulate cortex in treatment-resistant depression: a randomized control study. J. Affect. Disord. 225, 709-714. doi: 10.1016/j.jad.2017.09.008

Chiechio, S., Canonico, P. L., and Grilli, M. (2017). L-Acetylcarnitine: a mechanistically distinctive and potentially rapid-acting antidepressant drug. Int. J. Mol. Sci. 19:11. doi: 10.3390/ijms19010011

Chiechio, S., Copani, A., De Petris, L., Morales, M. E., Nicoletti, F., and Gereau, R. W. IV (2006). Transcriptional regulation of metabotropic glutamate receptor $2 / 3$ expression by the NF-kappaB pathway in primary dorsal root ganglia neurons: a possible mechanism for the analgesic effect of l-acetylcarnitine. Mol. Pain 2:20.

Chui, H., Gerstorf, D., Hoppmann, C. A., and Luszcz, M. A. (2015). Trajectories of depressive symptoms in old age: integrating age-, pathology-, and mortality-related changes. Psychol. Aging 30, 940-951. doi: 10.1037/pag000 0054

Cohen, S. P., Bhatia, A., Buvanendran, A., Schwenk, E. S., Wasan, A. D., Hurley, R. W., et al. (2018). Consensus guidelines on the use of intravenous ketamine infusions for chronic pain from the American Society of Regional Anesthesia and pain medicine, the American Academy of Pain Medicine, and the American Society of Anesthesiologists. Reg. Anesth. Pain Med. 43, 521-546.

Costello, C. A., Hu, T., Liu, M., Zhang, W., Furey, A., and Fan, Z. (2020). Metabolomics signature for non-responders to total joint replacement surgery in primary osteoarthritis patients: the Newfoundland osteoarthritis study. J. Orthop. Res. 38, 793-802. doi: 10.1002/jor.24529

Costigan, M., Scholz, J., and Woolf, C. J. (2009). Neuropathic pain: a maladaptive response of the nervous system to damage. Annu. Rev. Neurosci. 32, 1-32. doi: 10.1146/annurev.neuro.051508.135531

Cruccu, G., Di Stefano, G., Fattapposta, F., Jann, S., Padua, L., Schenone, A., et al. (2017). L-Acetyl-carnitine in patients with carpal tunnel syndrome: effects on nerve protection, hand function and pain. CNS Drugs 31, 1103-1111. doi: 10.1007/s40263-017-0476-2

Curtis, D. R., and Watkins, J. C. (1960). The excitation and depression of spinal neurones by structurally related amino acids. J. Neurochem. 6, 117-141. doi: 10.1111/j.1471-4159.1960.tb13458.x

Dalsasso, M., Tresin, P., Innocente, F., Veronese, S., and Ori, C. (2005). Lowdose ketamine with clonidine and midazolam for adult day care surgery. Eur. J. Anaesthesiol. 22, 67-68. doi: 10.1017/s0265021505210141

D’Amato, C., Morganti, R., Greco, C., Di Gennaro, F., Cacciotti, L., and Longo, S. (2016). Diabetic peripheral neuropathic pain is a stronger predictor of depression than other diabetic complications and comorbidities. Diabetes Vasc. Dis. Res. 2016, 418-428. doi: 10.1177/1479164116653240

Duncan, G. E., Miyamoto, S., and Lieberman, J. A. (2003). Chronic administration of haloperidol and olanzapine attenuates ketamine-induced brain metabolic activation. J. Pharmacol. Exp. Ther. 305, 999-1005. doi: 10.1124/jpet.102. 048140

Dworkin, R. H., Backonja, M., Rowbotham, M. C., Allen, R. R., Argoff, C. R., Bennett, G. J., et al. (2003). Advances in neuropathic pain: diagnosis, mechanisms, and treatment recommendations. Arch. Neurol. 60, 1524-1534.

Edwards, R. R., Dworkin, R. H., Sullivan, M. D., Turk, D. C., and Wasan, A. D. (2016). The role of psychosocial processes in the development and maintenance of chronic pain. J. Pain 17(9 Suppl), T70-T92. doi: 10.1016/j.jpain.2016. 01.001

Ezzati, A., Zammit, A. R., Lipton, M. L., and Lipton, R. B. (2019). The relationship between hippocampal volume, chronic pain, and depressive symptoms in older adults. Psychiatry Res. Neuroimaging 289, 10-12. doi: 10.1016/j.pscychresns. 2019.05.003

Fischer, A. S., Hagan, K. E., and Gotlib, I. H. (2021). Functional neuroimaging biomarkers of resilience in major depressive disorder. Curr. Opin. Psychiatry 34, 22-28. doi: 10.1097/YCO.0000000000000662

Fornasari, D. (2017). Pharmacotherapy for neuropathic pain: a review. Pain Ther. 6S1, 25-33. doi: 10.1007/s40122-017-0091-4

French, E. D. (1992). Competitive NMDA receptor antagonists attenuate phencyclidine-induced excitations of A10 dopamine neurons. Eur. J. Pharmacol. 217, 1-7. doi: 10.1016/0014-2999(92)90503-v

Freo, U. (2020). "New pain modulating drugs," in XIV Course of Neuromodulations, Venezia.

Freo, U., Carron, M., Innocente, F., Foletto, M., Nitti, D., and Ori, C. (2011). Effects of a-line autoregression index (AAI) monitoring on recovery after sevoflurane anesthesia for bariatric surgery. Obes. Surg. 21, 850-857. doi: 10.1007/s11695010-0150-y

Freo, U., Dam, M., and Ori, C. (2009). Cerebral metabolic effects of acetyl-1carnitine in rats during aging. Brain Res. 1259, 32-39. doi: 10.1016/j.brainres. 2008.12.025

Freo, U., Furnari, M., Ambrosio, F., Calcarella, G., and Briani, C. (2019a). AcetylL-carnitine in the treatment of chronic lumbar radiculopathy pain. J. Peripher. Nerv. Syst. 24, 22-23.

Freo, U., Furnari, M., Ambrosio, F., and Navalesi, P. (2020). Efficacy and tolerability of tapentadol for the treatment of chronic low back pain in elderly patients. Aging Clin. Exp. Res. doi: 10.1007/s40520-020-01586-0 [Epub ahead of print].

Freo, U., Merico, A., Ermani, M., and Ori, C. (2010). Chronic treatment with fluoxetine decreases cerebral metabolic responses to the 5-HT1A agonist 8-hydroxy-2(di-N-propylamino)tetralin and increases those to the 5HT2A/2C agonist 1-(2,5-dimethoxy-4-iodophenyl)-2-aminopropane and to the dopaminergic agonist apomorphine. Brain Res. 1335, 24-34. doi: 10.1016/j. brainres.2010.03.090

Freo, U., and Ori, C. (2002a). "Mapping cerebral metabolic and blood flow effects of general anesthetics," in Proceedings of the 17th Postgraduate Course in Critical Care Medicine, ed. A. Gullo (Milano: Springer), 877-891. doi: 10.1007/978-88470-2215-7_19

Freo, U., and Ori, C. (2002b). Opioid pharmacology of ketamine. Acta Anaesth. Ital. 53, 149-163.

Freo, U., and Ori, C. (2003). "Neuroimaging studies on ketamine," in Proceedings of the $18^{\text {th }}$ Postgraduate Course in Critical Care Medicine, ed. A. Gullo (Milano: Springer), 881-893. doi: 10.1007/978-88-470-2189-1_18

Freo, U., and Ori, C. (2004). Effects of anesthesia and recovery from ketamine racemate and enantiomers on regional cerebral glucose metabolism in rats. Anesthesiology 100, 1172-1178. doi: 10.1097/00000542-20040500000020

Freo, U., and Ori, C. (2009). "Ketamine for $3^{\text {rd }}$ millenium," in Proceedings of the STAT Meeting, Udine (Italy), Udine, 23-26.

Freo, U., Romualdi, P., and Kress, H. G. (2019b). Tapentadol for neuropathic pain: a review of clinical studies. J. Pain Res. 12, 1537-1551. doi: 10.2147/JPR. S190162

Freynhagen, R., Parada, H. A., Calderon-Ospina, C. A., Chen, J., Rakhmawati Emril, D., and Fernández-Villacorta, F. J. (2019). Current understanding of the mixed pain concept: a brief narrative review. Curr. Med. Res. Opin. 35, 1011-1018. doi: 10.1080/03007995.2018.1552042

Fukumoto, K., Iijima, M., and Chaki, S. (2016). ). The Antidepressant effects of an mGlu2/3 receptor antagonist and ketamine require AMPA receptor stimulation in the mPFC and subsequent activation of the 5-HT neurons in the DRN. Neuropsychopharmacology 41, 1046-1056. doi: 10.1038/npp. 2015.233

Gałecki, P., and Talarowska, M. (2017). The evolutionary theory of depression. Med. Sci. Monit. 23, 2267-2274. doi: 10.12659/msm.90 1240

García-Henares, J. F., Moral-Munoz, J. A., Salazar, A., and Del Pozo, E. (2018). Effects of ketamine on postoperative pain after remifentanil-based anesthesia 
for major and minor surgery in adults: a systematic review and meta-Analysis. Front. Pharmacol. 9:921. doi: 10.3389/fphar.2018.00921

Ghoneim, M. M., and O'Hara, M. W. (2016). Depression and postoperative complications: an overview. BMC Surg. 16:5. doi: 10.1186/s12893-016-0120-y

Global Burden of Disease Study 2013 Collaborators (2015). Global, regional, and national incidence, prevalence, and years lived with disability for 301 acute and chronic diseases and injuries in 188 countries, 1990-2013: a systematic analysis for the Global Burden of Disease Study 2013. The Lancet 386, 743-800. doi: 10.1016/S0140-6736(15)60692-4

Gould, T. D., Zarate, C. A. Jr., and Thompson, S. M. (2019). Molecular pharmacology and neurobiology of rapid-acting antidepressants. Annu. Rev. Pharmacol. Toxicol. 59, 213-236. doi: 10.1146/annurev-pharmtox-010617052811

Grieco, S. F., Cheng, Y., Eldar-Finkelman, H., Jope, R. S., and Beurel, E. (2016). Up-regulation of insulin-like growth factor 2 by ketamine requires glycogen synthase kinase-3 inhibition. Prog. Neuropsychopharmacol. Biol. Psychiatry 72, 49-54. doi: 10.1016/j.pnpbp.2016.08.008

Griego, E., and Galván, E. J. (2020). Metabotropic glutamate receptors at the aged mossy fiber - CA3 synapse of the hippocampus. Neuroscience 456, 95-105.

Hambrecht-Wiedbusch, V. S., Li, D., and Mashour, G. A. (2017). Paradoxical emergence: administration of subanesthetic ketamine during isoflurane anesthesia induces burst suppression but accelerates recovery. Anesthesiology 126, 482-494. doi: 10.1097/ALN.0000000000001512

Hanewinckel, R., Drenthen, J., van Oijen, M., Hofman, A., van Doorn, P. A., and Ikram, M. A. (2016). Prevalence of polyneuropathy in the general middleaged and elderly population. Neurology 87, 1892-1898. doi: 10.1212/WNL. 0000000000003293

Hashimoto, K. (2019). Rapid-acting antidepressant ketamine, its metabolites and other candidates: a historical overview and future perspective. Psychiatry Clin. Neurosci. 73, 613-627. doi: 10.1111/pcn.12902

Henter, I. D., de Sousa, R. T., Gold, P. W., Brunoni, A. R., Zarate, C. A. Jr., and Machado-Vieira, R. (2017). Mood therapeutics: novel pharmacological approaches for treating depression. Expert. Rev. Clin. Pharmacol. 10, 153-166. doi: 10.1080/17512433.2017.1253472

Heo, M., Pietrobelli, A., Fontaine, K., Sirey, J. A., and Faith, M. S. (2006). Depressive mood and obesity in US adults: comparison and moderation by sex, age, and race. Int. J. Obes. 30, 513-519. doi: 10.1038/sj.ijo.0803122

Highland, J. N., Zanos, P., Georgiou, P., and Gould, T. D. (2019). Group II metabotropic glutamate receptor blockade promotes stress resilience in mice. Neuropsychopharmacology 44, 1788-1796. doi: 10.1038/s41386-019-0380-1

Iadarola, N. D., Niciu, M. J., Richards, E. M., Vande Voort, J. L., Ballard, E. D., et al. (2015). Ketamine and other N-methyl-D-aspartate receptor antagonists in the treatment of depression: a perspective review. Ther. Adv. Chronic. Dis. 6, 97-114. doi: 10.1177/2040622315579059

Ikonomidou, C., and Turski, L. (2002). Why did NMDA receptor antagonists fail clinical trials for stroke and traumatic brain injury? Lancet Neurol. 1, 383-386. doi: 10.1016/s1474-4422(02)00164-3

Jelen, L. A., Young, A. H., and Stone, J. M. (2020). Ketamine: a tale of two enantiomers. J. Psychopharmacol. 35, 109-123. doi: 10.1177/0269881120959644

Jeong, H. S., Park, J. S., Yang, Y., Na, S. H., Chung, Y. A., and Song, I. U. (2017). Cerebral perfusion changes after acetyl-L-carnitine treatment in early Alzheimer's disease using single photon emission computed tomography. Dement. Neurocogn. Disord. 16, 26-31. doi: 10.12779/dnd.2017.16.1.26

Jevtovic-Todorovic, V., Wozniak, D. F., Benshoff, N. D., and Olney, J. W. (2001). A comparative evaluation of the neurotoxic properties of ketamine and nitrous oxide. Brain Res. 895, 264-267. doi: 10.1016/s0006-8993(01)02079-0

Jiang, M., Wang, M. H., Wang, X. B., Liu, L., Wu, J. L., Yang, X. L., et al. (2016). Effect of intraoperative application of ketamine on postoperative depressed mood in patients undergoing elective orthopedic surgery. J. Anesth. 30, 232237. doi: 10.1007/s00540-015-2096-7

Jiménez-Sánchez, L., Castañé, A., Pérez-Caballero, L., Grifoll-Escoda, M., LópezGil, X., Campa, L., et al. (2016). Activation of AMPA receptors mediates the antidepressant action of deep brain stimulation of the infralimbic prefrontal cortex. Cereb. Cortex 26, 2778-2789. doi: 10.1093/cercor/bhv133

Kelland, M. D., Soltis, R. P., Boldry, R. C., and Walters, J. R. (1993). Behavioral and electrophysiological comparison of ketamine with dizocilpine in the rat. Physiol. Behav. 54, 547-554. doi: 10.1016/0031-9384(93)90248-e
Khan, H. S., and Stroman, P. W. (2015). Inter-individual differences in pain processing investigated by functional magnetic resonance imaging of the brainstem and spinal cord. Neuroscience 307, 231-241. doi: 10.1016/j. neuroscience.2015.08.059

Khan, S. A., Keaser, M. L., Meiller, T. F., and Seminowicz, D. A. (2014). Altered structure and function in the hippocampus and medial prefrontal cortex in patients with burning mouth syndrome. Pain 155, 1472-1480. doi: 10.1016/j. pain.2014.04.022

Kokkinou, M., Ashok, A. H., and Howes, O. D. (2018). The effects of ketamine on dopaminergic function: meta-analysis and review of the implications for neuropsychiatric disorders. Mol. Psychiatry 23, 59-69. doi: 10.1038/mp. 2017.190

Kroenke, K., Wu, J., Bair, M. J., Krebs, E. E., Damush, T. M., and Tu, W. (2011). Reciprocal relationship between pain and depression: a 12-month longitudinal analysis in primary care. J. Pain 12, 964-973. doi: 10.1016/j.jpain.2011.03.003

Kudoh, A., Takahira, Y., Katagai, H., and Takazawa, T. (2002). Small-dose ketamine improves the postoperative state of depressed patients. Anesthes. Anal. 95, 114-118. doi: 10.1097/00000539-200207000-00020

Kuratsune, H., Yamaguti, K., Lindh, G., Evengård, B., Hagberg, G., Matsumura, K., et al. (2002). Brain regions involved in fatigue sensation: reduced acetylcarnitine uptake into the brain. Neuroimage 17, 1256-1265. doi: 10.1006/nimg.2002. 1260

Li, B. J., Friston, K., Mody, M., Wang, H. N., Lu, H. B., and Hu, D. W. (2018). A brain network model for depression: from symptom understanding to disease intervention. CNS Neurosci. Therap. 24, 1004-1019. doi: 10.1111/cns.12998

Li, C. T., Chen, M. H., Lin, W. C., Hong, C. J., Yang, B. H., and Liu, R. S. (2016). The effects of low-dose ketamine on the prefrontal cortex and amygdala in treatment-resistant depression: a randomized controlled study. Hum. Brain Mapp. 37, 1080-1090. doi: 10.1002/hbm.23085

Li, S., Li, Q., Li, Y., Li, L., Tian, H., and Sun, X. (2015). Acetyl-L-carnitine in the treatment of peripheral neuropathic pain: a systematic review and meta-analysis of randomized controlled trials. PLoS One 10:e0119479. doi: 10.1371/journal. pone.0119479

Liao, Y., Tang, J., Ma, M., Wu, Z., Yang, M., and Wang, X. (2010). Frontal white matter abnormalities following chronic ketamine use: a diffusion tensor imaging study. Brain 133(Pt 7), 2115-2122. doi: 10.1093/brain/ awq131

Lucassen, P. J., Pruessner, J., Sousa, N., Almeida, O. F., Van Dam, A. M., Rajkowska, G., et al. (2014). Neuropathology of stress. Acta Neuropathol. 127, 109-135.

Luppino, F. S., de Wit, L. M., Bouvy, P. F., Stijnen, T., Cuijpers, P., and Penninx, B. W. (2010). Overweight, obesity, and depression: a systematic review and meta-analysis of longitudinal studies. Arch. Gen. Psychiatry 67, 220-229. doi: 10.1001/archgenpsychiatry.2010.2

Marton, T., Barnes, D. E., Wallace, A., and Woolley, J. D. (2019). Concurrent use of buprenorphine, methadone, or naltrexone does not inhibit ketamine's antidepressant activity. Biol. psychiatry 85, e75-e76. doi: 10.1016/j.biopsych. 2019.02.008

Masaki, Y., Kashiwagi, Y., Watabe, H., and Abe, K. (2019). (R)- and (S)-ketamine induce differential fMRI responses in conscious rats. Synapse 73:e22126. doi: 10.1002/syn.22126

Meng, W., Adams, M. J., Reel, P., Rajendrakumar, A., Huang, Y., and Deary, I. J. (2020). Genetic correlations between pain phenotypes and depression and neuroticism. Eur. J. Hum. Genet. EJHG 28, 358-366. doi: 10.1038/s41431-0190530-2

Meyer, T., Cooper, J., and Raspe, H. (2007). Disabling low back pain and depressive symptoms in the community-dwelling elderly: a prospective study. Spine 32, 2380-2386. doi: 10.1097/brs.0b013e3181557955

Mills, S. E. E., Nicolson, K. P., and Smith, B. H. (2019). Chronic pain: a review of its epidemiology and associated factors in population-based studies. Br. J. Anaesth. 123, e273-e283.

Moghaddam, B., Adams, B., Verma, A., and Daly, D. (1997). Activation of glutamatergic neurotransmission by ketamine: a novel step in the pathway from NMDA receptor blockade to dopaminergic and cognitive disruptions associated with the prefrontal cortex. J. Neurosci. 17, 2921-2927. doi: 10.1523/jneurosci. 17-08-02921.1997

Molton, I. R., and Terrill, A. L. (2014). Overview of persistent pain in older adults. Am. Psychol. 69, 197-207. doi: 10.1037/a0035794 
Moriguchi, S., Takamiya, A., Noda, Y., Horita, N., Wada, M., Tsugawa, S., et al. (2019). Glutamatergic neurometabolite levels in major depressive disorder: a systematic review and meta-analysis of proton magnetic resonance spectroscopy studies. Mol. Psychiatry 24, 952-964. doi: 10.1038/s41380-0180252-9

Mutso, A. A., Radzicki, D., Baliki, M. N., Huang, L., Banisadr, G., and Centeno, M. V. (2012). Abnormalities in hippocampal functioning with persistent pain. J. Neurosci. 32, 5747-5756. doi: 10.1523/jneurosci.0587-12.2012

Nasca, C., Bigio, B., Lee, F. S., Young, S. P., Kautz, M. M., and Albright, A. (2018). Acetyl-L-carnitine deficiency in patients with major depressive disorder. Proc. Natl. Acad. Sci. U.S.A. 115, 8627-8632.

Nasca, C., Xenos, D., Barone, Y., Caruso, A., Scaccianoce, S., Matrisciano, F., et al. (2013). L-acetylcarnitine causes rapid antidepressant effects through the epigenetic induction of mGlu2 receptors. Proc. Natl. Acad. Sci. U.S.A. 110, 4804-4809. doi: 10.1073/pnas.1216100110

Nicholson, B., and Verma, S. (2004). Comorbidities in chronic neuropathic pain. Pain Med. 5S1, S9-S27.

Nijland, L. M. G., de Castro, S. M. M., and van Veen, R. N. (2020). Risk factors associated with prolonged hospital stay and readmission in patients after primary bariatric surgery. Obes. Surg. 30, 2395-2402. doi: 10.1007/s11695-02004507-2

Ong, W. Y., Stohler, C. S., and Herr, D. R. (2019). Role of the prefrontal cortex in pain processing. Mol. Neurobiol. 56, 1137-1166. doi: 10.1007/s12035-0181130-9

Onofrj, M., Ciccocioppo, F., Varanese, S., di Muzio, A., Calvani, M., and Chiechio, S. (2013). Acetyl-L-carnitine: from a biological curiosity to a drug for the peripheral nervous system and beyond. Expert. Rev. Neurother. 13, 925-936. doi: 10.1586/14737175.2013.814930

Orhurhu, V., Claus, L. E., Vashisht, R., and Cohen, S. P. (2020). Ketamine Toxicity. Available online at: https://www.ncbi.nlm.nih.gov/books/NBK541087 (accessed July 8, 2020).

Orhurhu, V., Orhurhu, M. S., Bhatia, A., and Cohen, S. P. (2019). Ketamine infusions for chronic pain: a systematic review and meta-analysis of randomized controlled rrials. Anesth. Analg. 129, 241-254. doi: 10.1213/ANE. 0000000000004185

Ori, C., Dalsasso, M., and Freo, U. (2003). "Ketamine, a general anaesthetic agent and more. A review on its use in and out the clinical setting," in Anaesthesia, Pain, Intensive Care and Emergency Medicine. $18^{\text {th }}$ Postgraduate Course in Critical Care Medicine, ed. A. Gullo (Milano: Spinger), 863-979. doi: 10.1007/ 978-88-470-2189-1_17

Ori, C., Freo, U., Pizzolato, G., and Dam, M. (2002). Effects of acetyl-L-carnitine on regional cerebral glucose metabolism in awake rats. Brain Res. 951, 330-335. doi: 10.1016/s0006-8993(02)03290-0

O'Sullivan, C. (2004). The psychosocial determinants of depression: a lifespan perspective. J. Nerv. Ment. Dis. 192, 585-594. doi: 10.1097/01.nmd.0000138225. 19549.dd

Pelletier, R., Higgins, J., and Bourbonnais, D. (2015). Is neuroplasticity in the central nervous system the missing link to our understanding of chronic musculoskeletal disorders? BMC Musculoskelet. Disord. 12:16-25. doi: 10.1186/ s12891-015-0480-y

Pereira, A. C., Lambert, H. K., Grossman, Y. S., Dumitriu, D., Waldman, R., and Jannetty, S. K. (2014). Glutamatergic regulation prevents hippocampaldependent age-related cognitive decline through dendritic spine clustering. Proc. Natl. Acad. Sci U.S.A. 111, 18733-18738. doi: 10.1073/pnas.1421285111

Pereira, V., and Goudet, C. (2019). Emerging trends in pain modulation by metabotropic glutamate receptors. Front. Mol. Neurosci. 11:464. doi: 10.3389/ fnmol.2018.00464

Petrovic, P., Kalso, E., Petersson, K. M., and Ingvar, M. (2002). Placebo and opioid analgesia- imaging a shared neuronal network. Science 295, 1737-1740. doi: $10.1126 /$ science. 1067176

Post, R. M. (2018). Myriad of implications of acetyl-L-carnitine deficits in depression. Proc. Natl. Acad. Sci. U.S.A. 115, 8475-8477. doi: 10.1073/pnas. 1811389115

Pu, J., Liu, Y., Zhang, H., Tian, L., Gui, S., and Yu, Y. (2020). An integrated meta-analysis of peripheral blood metabolites and biological functions in major depressive disorder. Mol. Psychiatry 20. doi: 10.1038/s41380-0200645-4
Rahman, R., Ibaseta, A., Reidler, J. S., Andrade, N. S., Skolasky, R. L., and Riley, L. H. (2020). Changes in patients' depression and anxiety associated with changes in patient-reported outcomes after spine surgery. J. Neurosurg. Spine 31, 1-20. doi: 10.3171/2019.11.SPINE19586

Riggs, L. M., and Gould, T. D. (2021). Ketamine and the future of rapidacting antidepressants. Annu. Rev. Clin. Psychol. doi: 10.1146/annurev-clinpsy072120-014126 [Epub ahead of print].

Robinson, B. L., Dumas, M., Cuevas, E., Gu, Q., Paule, M. G., and Ali, S. F. (2016). Distinct effects of ketamine and acetyl L-carnitine on the dopamine system in zebrafish. Neurotoxicol. Teratol. 54, 52-60. doi: 10.1016/j.ntt.2016.02. 004

Robu, B., and Lavand'homme, P. (2019). Targeting the affective component of pain with ketamine: a tool to improve the postoperative experience? Eur. J. Anaesthesiol. 36, 4-5. doi: 10.1097/eja.0000000000000915

Rodríguez-Cano, E., Alonso-Lana, S., Sarró, S., Fernández-Corcuera, P., Goikolea, J. M., Vieta, E., et al. (2017). Differential failure to deactivate the default mode network in unipolar and bipolar depression. Bipolar Disord. 19, 386-395. doi: 10.1111/bdi.12517

Romeo, B., Choucha, W., Fossati, P., and Rotge, J. Y. (2015). Meta-analysis of short- and mid-term efficacy of ketamine in unipolar and bipolar depression. Psychiatry Res. 230, 682-688. doi: 10.1016/j.psychres.2015.10.032

Sapkota, K., Mao, Z., Synowicki, P., Lieber, D., Liu, M., Ikezu, T., et al. (2016). GluN2D N-methyl-d-aspartate receptor subunit contribution to the stimulation of brain activity and gamma oscillations by ketamine: implications for schizophrenia. J. Pharmacol. Exp. Ther. 356, 702-711. doi: 10.1124/jpet.115. 230391

Scholz, J., Finnerup, N. B., Attal, N., Aziz, Q., Baron, R., and Bennett, M. I. (2019). The IASP classification of chronic pain for ICD-11: chronic neuropathic pain. Pain 160, 53-59.

Shao, J., Meng, C., Tahmasian, M., Brandl, F., Yang, Q., Luo, G., et al. (2018). Common and distinct changes of default mode and salience network in schizophrenia and major depression. Brain Imaging Behav. 12, 1708-1719. doi: 10.1007/s11682-018-9838-8

Sharkey, J., Ritchie, I. M., Butcher, S. P., and Kelly, J. S. (1996). Comparison of the patterns of altered cerebral glucose utilisation produced by competitive and non-competitive NMDA receptor antagonists. Brain Res. 735, 67-82. doi: 10.1016/0006-8993(96)00574-4

Sheng, J., Liu, S., Wang, Y., Cui, R., and Zhang, X. (2017). The link between depression and chronic pain: neural mechanisms in the brain. Neural Plast. 2017:9724371. doi: 10.1155/2017/9724371

Skolasky, R. L., Riley, L. H. III, Maggard, A. M., and Wegener, S. T. (2012). The relationship between pain and depressive symptoms after lumbar spine surgery. Pain 153, 2092-2096. doi: 10.1016/j.pain.2012.06.026

Smeland, O. B., Meisingset, T. W., Borges, K., and Sonnewald, U. (2012). Chronic acetyl-1-carnitine alters brain energy metabolism and increases noradrenaline and serotonin content in healthy mice. Neurochem. Int. 61, 100-107. doi: 10. 1016/j.neuint.2012.04.008

Solhaug, H. I., Romuld, E. B., Romild, U., and Stordal, E. (2012). Increased prevalence of depression in cohorts of the elderly: an 11-year follow-up in the general population - the HUNT study. Int. Psychogeriatr. 24, 151-158. doi: 10.1017/S1041610211001141

Subramani, Y., Nagappa, M., Wong, J., Patra, J., and Chung, F. (2017). Death or near-death in patients with obstructive sleep apnoea: a compendium of case reports of critical complications. Br. J. Anaesth. 119, 885-899. doi: 10.1093/bja/ aex341

Tanaka, M., Nakamura, F., Mizokawa, S., Matsumura, A., Matsumura, K., and Watanabe, Y. (2003). Role of acetyl-L-carnitine in the brain: revealed by bioradiography. Biochem. Biophys. Res. Commun. 306, 1064-1069. doi: 10. 1016/s0006-291x(03)01103-3

Teffer, K., and Semendeferi, K. (2012). Human prefrontal cortex: evolution, development, and pathology. Prog. Brain Res. 195, 191-218. doi: 10.1016/B9780-444-53860-4.00009-X

Thompson, J. M., and Neugebauer, V. (2019). Cortico-limbic pain mechanisms. Neurosci. Lett. 702, 15-23. doi: 10.1016/j.neulet.2018.11.037

Tolu, P., Masi, F., Leggio, B., Scheggi, S., Tagliamonte, A., De Montis, M. G., et al. (2002). Effects of long-term acetyl-L-carnitine administration in rats: I. increased dopamine output in mesocorticolimbic areas and protection toward 
acute stress exposure. Neuropsychopharmacology 27, 410-420. doi: 10.1016/ s0893-133x (02)00306-8

Toth, E., Harsing, L. G. Jr., Sershen, H., Ramacci, M. T., and Lajtha, A. (1993). Effect of acetyl-L-carnitine on extracellular amino acid levels in vivo in rat brain regions. Neurochem. Res. 18, 573-578. doi: 10.1007/BF00966933

Ushinsky, A., Reinhardt, L. E., Simmons, A. N., and Strigo, I. A. (2013). Further evidence of emotional allodynia in unmedicated young adults with major depressive disorder. PLoS One 8:e80507. doi: 10.1371/journal.pone.0080507

van Ettinger-Veenstra, H., Lundberg, P., Alföldi, P., Södermark, M., GravenNielsen, T., Sjörs, A., et al. (2019). Chronic widespread pain patients show disrupted cortical connectivity in default mode and salience networks, modulated by pain sensitivity. J. Pain Res. 12, 1743-1755. doi: 10.2147/JPR. S189443

Volkow, N. D., Michaelides, M., and Baler, R. (2019). The neuroscience of drug reward and addiction. Physiol. Rev. 99, 2115-2140. doi: 10.1152/physrev.00014. 2018

Wang, J., Echevarria, G. C., Doan, L., Ekasumara, N., Calvino, S., Chae, F., et al. (2019). Effects of a single subanaesthetic dose of ketamine on pain and mood after laparoscopic bariatric surgery: a randomised double-blind placebo controlled study. Eur. J. Anaesthesiol. 36, 16-24. doi: 10.1097/EJA. 0000000000000860

Wang, S. M., Han, C., Lee, S. J., Patkar, A. A., Masand, P. S., and Pae, C. U. (2014). A review of current evidence for acetyl-l-carnitine in the treatment of depression. J. Psychiatr. Res. 53, 30-37. doi: 10.1016/j.jpsychires.2014.02.005

Williams, N. R., Heifets, B. D., Blasey, C., Sudheimer, K., Pannu, J., Pankow, H., et al. (2018). Attenuation of antidepressant effects of ketamine by opioid receptor antagonism. Am. J. Psychiatry 175, 1205-1215. doi: 10.1176/appi.ajp. 2018.18020138

Witkin, J. M., Monn, J. A., Schoepp, D. D., Li, X., Overshiner, C., Mitchell, S. N., et al. (2016). The rapidly acting antidepressant ketamine and the mGlu2/3 receptor antagonist LY341495 rapidly engage dopaminergic mood circuits. J. Pharmacol. Exp. Therap. 358, 71-82. doi: 10.1124/jpet.116.233627
Yang, C., Yang, J., Luo, A., and Hashimoto, K. (2019). Molecular and cellular mechanisms underlying the antidepressant effects of ketamine enantiomers and its metabolites. Trans. Psychiatry 9:280. doi: 10.1038/s41398-019-0624-1

Yoon, G., Petrakis, I. L., and Krystal, J. H. (2019). Association of combined naltrexone and ketamine with depressive symptoms in a case series of patients with depression and alcohol use disorder. JAMA Psychiatry 76, 337-338. doi: 10.1001/jamapsychiatry.2018.3990

Zammataro, M., Chiechio, S., Montana, M. C., Traficante, A., Copani, A., and Nicoletti, F. (2011). ). mGlu2 metabotropic glutamate receptors restrain inflammatory pain and mediate the analgesic activity of dual mGlu2/mGlu3 receptor agonists. Mol. Pain 7:6.

Zanos, P., Moaddel, R., Morris, P. J., Georgiou, P., Fischell, J., Elmer, G. I., et al. (2016). NMDAR inhibition-independent antidepressant actions of ketamine metabolites. Nature 533, 481-486. doi: 10.1038/nature 17998

Zhang, K., and Hashimoto, K. (2019). Lack of opioid system in the antidepressant actions of ketamine. Biol. Psychiatry, 85, e25-e27. doi: 10.1016/j.biopsych.2018. 11.006

Zhang, Y., Mao, Z., Pan, L., Ling, Z., Liu, X., Zhang, J., et al. (2018). Dysregulation of pain- and emotion-related networks in trigeminal neuralgia. Front. Hum. Neurosci. 12:107. doi: 10.3389/fnhum.2018.00107

Conflict of Interest: The authors declare that the research was conducted in the absence of any commercial or financial relationships that could be construed as a potential conflict of interest.

Copyright (c) 2021 Freo, Brugnatelli, Turco and Zanette. This is an open-access article distributed under the terms of the Creative Commons Attribution License (CC BY). The use, distribution or reproduction in other forums is permitted, provided the original author(s) and the copyright owner(s) are credited and that the original publication in this journal is cited, in accordance with accepted academic practice. No use, distribution or reproduction is permitted which does not comply with these terms. 